\title{
THE LEFT LABOURITES AND THE GENERAL STRIKE OF 1926 IN THE UK
}

\author{
Evgeniya G. Blosfeld \\ Volgograd State Social-Pedagogical University, Volgograd, Russian Federation
}

\begin{abstract}
The author analyses the left labourites' attitude to the interaction of the Labour Party and trade unions and use of general strike as a means of the social struggle. Besides the article analyses the left labourites' estimation of 1926 general strike and the causes of the defeat, and the strike of the miners who decided to continue it.

The left labourites defended the branch principle of the trade unions' organization based on the shopstewards' model which was better adopted for the strike struggle. The left labourites took into account that the general structure of the labour movement would remain the same, but the Labour Party would take over the leadership from trade unions.

The left labourites supported the peaceful way of transition to socialism and they considered the general strike to be analogy of social revolution or a means of pressure of the government for nationalization of the main economic branches and the improvement of the workers' life conditions. Under extreme circumstances, the general strike was considered to be a means to prevent antidemocratic revolution.

Evaluating the general strike of 1926, the author marks the absence of unity in the leadership, hesitations and inconsistency of the left labourites themselves. They didn't give a single proposal about the improvement of the working-class movement organization except of state British Trade Unions Congress. As a result, the criticism of the General Council's renegade position was bestowed upon the leadership of the Miners Federation who didn't submit to the General Council order to stop the strike.

Key words: general strike, working class movement, left labourites, trade unions, Great Britain.

Citation. Blosfeld E.G. The Left Labourites and the General Strike of 1926 in the UK. Vestnik Volgogradskogo gosudarstvennogo universiteta. Seriya 4, Istoriya. Regionovedenie. Mezhdunarodnye otnosheniya [Science Journal of Volgograd State University. History. Area Studies. International Relations], 2017, vol. 22, no. 6, pp. 145-153. (in Russian). DOI: https://doi.org/10.15688/jvolsu4.2017.6.14
\end{abstract}

УДК 94(4)

ББК 63,3(4Вел)6
Дата поступления статьи: 29.05.2017

Дата принятия статьи: 10.11 .2017

\section{ЛЕВЫЕ ЛЕЙБОРИСТЫ И ВСЕОБЩАЯ СТАЧКА 1926 ГОДА В ВЕЛИКОБРИТАНИИ}

\author{
Евгения Григорьевна Блосфельд \\ Волгоградский государственный социально-педагогический университет, \\ г. Волгоград, Российская Федерация
}

\footnotetext{
Аннотация. Автор анализирует позицию левых лейбористов в отношении взаимодействия Лейбористской партии и тред-юнионов и использования всеобщей стачки как средства борьбы. Анализируется оценка левыми лейбористами всеобщей стачки 1926 г. и причин ее поражения, а также стачки горняков, которые 흘 решили продолжать забастовку самостоятельно.

Л Левые отстаивали отраслевой принцип организации профсоюзов по образцу шоп-стюардов, которые были лучше приспособлены для стачечной борьбы. При этом они имели в виду, что общая структура рабочего движения останется прежней, но руководящая роль будет принадлежать не тред-юнионам, а Лейбористской партии. Защищая мирный переход к социализму, они рассматривали всеобщую стачку либо как тождественную социальной революции, либо как средство давления на правительство для улучшения положения рабочих, для национализации ключевых отраслей промышленности, в крайнем случае как средство против антидемократического переворота.
} 
При оценке всеобщей стачки 1926 г. отмечается отсутствие единства в руководстве стачкой, колебания и непоследовательность самих левых лейбористов, которые не предложили мер по улучшению организации рабочего движения, кроме реорганизации Британского конгресса тред-юнионов - БКТ. Критика ренегатской позиции Генсовета БКТ в результате была перенесена на руководство Федерации горняков, не подчинившихся приказу Генсовета прекратить стачку.

Ключевые слова: всеобщая стачка, движение рабочего класса, левые лейбористы, тред-юнионы, горняки.

Цитирование. Блосфельд Е. Г. Левые лейбористы и всеобщая стачка 1926 года в Великобритании // Вестник Волгоградского государственного университета. Серия 4, История. Регионоведение. Международные отношения. - 2017. - Т. 22, № 6. - C. 145-153. - DOI: https://doi.org/10.15688/jvolsu4.2017.6.14

Вопреки всем заявлениям, что рабочего класса сейчас нет, упадку интереса к рабочему движению на всей планете сегодня происходят забастовки, все чаще они происходят и в России.

И мы хотим оживить страницы истории английского рабочего движения 20-х гг. прошлого века, периода всеобщей стачки 1926 года. Они представляют интерес: сегодня рабочие лидеры и рабочие питают во многом те же иллюзии и совершают те же ошибки, что и левые лейбористы того периода. Перед ними так же стоят задачи организованности и боевитости.

Со второй половины 1920-х гг. рабочее движение Великобритании развивалось в условиях депрессии и начинающегося мирового экономического кризиса при одновременном общем спаде революционных настроений и надежд 1918-го - начала 1920-х годов. Это определило иной его характер, иное поведение и лозунги лидеров, иную внешнеполитическую реакцию на забастовки.

Левые лейбористы не были объединены в какую-то отдельную группу: они группировались непосредственно в тред-юнионах (Федерация горняков, Объединенный союз машиностроителей, некоторые небольшие союзы), в Независимой рабочей партии (НРП), являющейся коллективным членом Лейбористской партии. Все левые лейбористы объединялись вокруг еженедельной газеты «Lansbury's Labour Weekly», издаваемой Д. Лэнсбери. Они взаимодействовали друг с другом, выступая в одних и тех же печатных органах, иногда расходясь по целому ряду вопросов. Их позиция отличалась от официальной точки зрения.

Левые лейбористы отстаивали единство рабочего класса в борьбе с капитализмом как важный залог успеха в деле защиты интересов рабочего класса. Это единство они мыслили прежде всего как единство тредюнионов. Требуя от исполкома Лейбористской партии возглавить это движение и сделать его инструментом в борьбе с капитализмом, они видели проблему по-иному, чем большинство историков, социологов и официальных руководителей.

Последние считали, что эффективному руководству и выполнению социалистических целей мешает автоматическое включение профсоюзов в состав Лейбористской партии. Пункт 1 устава партии 1918 г. давал тредюнионам преимущество при выборах в исполком. Так был оформлен негласный компромисс, обеспечивающий Лейбористской партии финансовую поддержку тред-юнионов. Но основная масса членов тред-юнионов отнюдь не была проникнута социалистическими настроениями, что позволяло лейбористскому руководству оправдывать соглашательскую позицию в борьбе с капитализмом. Левые же лейбористы, критикуя указанный пункт устава, в то же время видели основную задачу не в изменении структуры партии, а в укреплении связей с тред-юнионами в рамках этой структуры, в ведении целенаправленной социалистической пропаганды внутри профсоюзов и поддержке борьбы трудящихся за повседневные нужды. Борьбу с безработицей они считали задачей всех рабочих, требуя привлекать безработных в тред-юнионы.

На наш взгляд, позиция левых лейбористов была единственно верной. Основная масса трудящихся Великобритании издавна организована в тред-юнионы, значительная часть которых входит в Британский конгресс тредюнионов (БКТ) и находится под влиянием Лейбористской партии, но разделена по цеховому принципу. Вопрос о единстве рабочего класса в этих условиях означал прежде всего единство внутри самой организации тред-юни- 
онов, их солидарность, тем более, что значительная их часть оставалась под буржуазным влиянием.

В условиях наступления буржуазии старой тред-юнионистской тенденции со слабым социалистическим сознанием надо было противопоставить сплоченное, политически воспитанное рабочее движение. Поэтому левое крыло в качестве первостепенной задачи и выдвинуло достижение единства рабочего движения. Главным рычагом решения этой задачи, по мнению левых лейбористов, была реорганизация тред-юнионов по производственному принципу, создание крупных отраслевых союзов, они пытались использовать в новых союзах опыт организации шоп-стюардов. Постановка этой задачи в английском рабочем движении была заслугой гильдейских социалистов, активного радикального течения внутри лейборизма, которое восприняло эту идею из опыта революционных российских рабочих. Д. Коул справедливо писал, что рабочие в Британии до сих пор ощущают себя не представителями рабочего класса в целом, а представителями того или иного союза, обособленного от других. Борясь за единство действий рабочего класса, Д. Коул настаивал на централизации профсоюзов и, в частности, считал, что Федерация горняков (наиболее активный профсоюз с сильным левым влиянием) должна быть преобразована в Национальный союз, лидеры которого защищали бы интересы не своих шахт, а интересы всех шахтеров [8, Мау 16, p. 13].

Левые лейбористы обоснованно говорили, что «единой силе капитала должна быть противопоставлена единая сила труда» $[9$, Febr. 20, p. 4].

Надо заметить, что аналогичную позицию занимали и коммунисты. Так, Г. Поллит на 27-й конференции Лейбористской партии требовал перестройки тред-юнионов на индустриальной и более демократичной основе [17, p. 241].

Однако линия на централизацию и создание сильных производственных тред-юнионов не могла полностью обеспечить долговременный успех. Совместить старую и новую формы тред-юнионов было трудно, поскольку они различались по принципам и методам действий. Новые организации возникали в ходе стачечной борьбы и были приспособлены для нее, в руководстве же старых союзов преобладало мнение о стачке как крайнем средстве, с исключительно экономическими требованиями; политические требования не должны были выдвигаться, даже если они соответствовали экономическим интересам рабочих. Руководство БКТ принадлежало правым, имевшим установку только на переговоры с предпринимателями и правительством. Генсовет БКТ тормозил «прямые», то есть забастовочные, действия. Поэтому требование централизации тред-юнионистского движения и создания производственных (отраслевых) союзов вступало в противоречие с консервативным руководством БКТ, не заинтересованным в активизации, боевитости движения.

Понимая это, левые лейбористы требовали демократического представительства в центральных органах тред-юнионов, избрания их всеми трудящимися дистриктов и прямого представительства их в БКТ [8, Mar. 7, p. 4; June 27, p. 4]. Д. Коул писал: «Пока мы не признаем, что местная солидарность - необходимая основа национальной и международной солидарности, что профсоветы так же важны, как национальные союзы и сам конгресс, мы не достигнем действительной эффективности местных организаций» $[8$, Мау 7 , p. 4]. Левые полагали, что в результате демократизации избрания профсоюзных лидеров последние будут действительно представлять интересы рабочих. Они считали забастовку правомерным средством в борьбе за национализацию и рабочий контроль. Всеобщая стачка рассматривалась ими и как мера предотвращения военной опасности, как гарантия мирного пути к социализму, способ борьбы с саботажем капиталистов при проведении социалистических преобразований. «Единственный путь сделать революцию успешной, если она начнется, - писал Д. Коул, - лежит в наличии сильного и сплоченного тред-юнионистского движения» [8, July 18, p. 6].

И это не было проявлением синдикализма, как считают некоторые историки, хотя синдикалистские настроения действительно были свойственны гильдейским социалистам, но в целом мнение о синдикализме английских тред-юнионов было явно преувеличенным.

Левые в НРП продолжали добиваться непосредственной работы своих членов в 
тред-юнионах. Через профсоюзы они стремились сплотить все рабочее движение на платформе левого крыла, независимо от того, коммунисты это или лейбористы, члены НРП или Кооперативной партии. Одновременно они рассматривали профсоюзы как опору деятельности парламентской лейбористской фракции. Эти задачи подчеркивал Д. Уитли в интервью левой, руководимой коммунистами, газете «Sunday Worker» [18, Apr. 5, p. 9]. Выступая на митинге шахтеров в Глазго в 1925 г., он говорил, что надо превратить палату общин в агитационную платформу, а за пределами парламента осуществлять руководство рабочим классом. «Мы должны в гораздо большей степени вовлечь тред-юнионы в политическую борьбу и бороться, как единая армия» (цит. по: [12, p. 196]).

Однако со стороны некоторых профлидеров левого крыла, в частности представителей НРП, это стремление левых лейбористов к политизации тред-юнионистского движения порой вызывало сопротивление. Так, секретарь Федерации горняков А. Кук писал: «Оставьте тред-юнионы в покое, мы, как и прежде, обойдемся без советов суперинтеллектуалов из НРП» $[15$, Sept. 19, p. 9]. Это было вызвано прежде всего опасением подчинения действий тред-юнионов исключительно целям парламентской борьбы. Одновременно это подчеркивало слабую связь НРП с рабочим движением, а также свидетельствовало о наличии некоторых тенденций секционализма и синдикализма в профсоюзах. Хотя мы не склонны присоединяться к тем исследователям, которые считают, что вплоть до 1926 г. левые лейбористы находились на позициях синдикализма.

В то же время активность рабочего движения в 1920-х гг. породила у части левых лейбористов, как и у коммунистов, предчувствие близкого падения капитализма. Это настроение (или опасение) разделялось обществом в Европе и даже в США. В этой надежде левые лейбористы отводили тред-юнионам значительную роль в процессе преобразования общества. Желая мирно организованной революции, левые надеялись направить борьбу тред-юнионов в русло радикальных преобразований общества в социалистическом духе, одновременно удерживая рабочих от вооруженной борьбы. В таком духе высказывались и Д. Коул, и Д. Лэнсбери, и Н. Эйнджел. Нельзя, однако, объяснять стремление левых лейбористов обеспечить политическое руководство английскому рабочему движению стремлением отвлечь рабочих от революционных действий [4, с. 57]. При опоре на организованные рабочие выступления, на стачки левые лейбористы стремились к ненасильственному переходу к социализму, но мыслили этот переход утопически.

Действия рабочего класса и самих левых лейбористов в 1920-е гг. не были вызваны только воздействием коммунистической агитации, как полагают некоторые историки (см. напр.: [13, p. 178-179]), хотя отрицать его нельзя. Пример Советского Союза был важен для них, особенно в условиях послевоенной депрессии. Некоторые из леволейбористских идеологов, наиболее тесно связанные с рабочими организациями, готовы были поддержать и вооруженные выступления рабочих.

Важным рубежом в развитии леволейбористской оппозиции явилась всеобщая стачка 1926 г. и последовавшая после ее поражения изнурительная стачка горняков. Эта борьба, где кратковременное торжество рабочего класса и левых сменилось крахом всех надежд и иллюзий, вскрыла все слабости рабочего движения: тред-юнионов, Лейбористской партии вообще и левых лейбористов в частности.

Всеобщей стачке посвящено немало исследований, гораздо меньше специальных работ о забастовке шахтеров. Очень обстоятельной и аналитической является статья П.В. Гурович и А.Г. Судейкина [3], однако левому лейбористскому крылу в ней внимание не уделено: она описывает обстоятельства возникновения, ход самой забастовки и анализирует причины ее поражения. В статье, к сожалению, не учитывается международная обстановка, в которой проходила стачка, а это имеет очень большое значение при анализе ее результатов.

В Англии, в отличие от нашей историографии, за последние годы вышло немало работ, которые, однако, по существу также игнорируют позицию левого лейборизма, и они в большей степени уделяют внимание характеристике особенностей хода забастовки горняков в шахтерских районах (см. напр.: $[5 ; 11 ; 14])$. 
Нас в большей мере интересует позиция левого лейборизма до и в период стачки (см. также: [2]).

Всеобщая стачка началась 4 мая 1926 г. после объявления локаута шахтерам на основе выводов государственной комиссии Г. Сэмюэля о необходимости закрытия ряда шахт и понижения зарплаты шахтерам. Федерация горняков, насчитывавшая 945 тысяч рабочих, заявила о своем несогласии. БКТ поддержал горняков и принял решение о всеобщей стачке. Более 4 миллионов членов тред-юнионов из общего числа 5,5 миллионов начали всеобщую забастовку. Генсовет получил право полного распоряжения производством, шахтовладельцы и руководители железнодорожного транспорта были бессильны. Рабочие требовали открытия шахт, сохранения отрасли в том же объеме, увеличения зарплаты, эмбарго на ввоз угля. Это был пик борьбы английского рабочего класса в 1920-е годы. Видные левые лейбористские деятели Э. Уилкинсон и Г. Брэйлсфорд считали стачку потрясением не только для правительства, но и для самого лейбористского движения. Перефразируя название известной книги Д. Рида, они назвали свои статьи «Десять дней, которые потрясли кабинет» и «Девять дней, которые потрясли Генсовет» (см.: [9, Мау 22, p. 8-9; 12, Мау 21, p. 6-7]).

Но 12 мая Генсовет неожиданно объявил о прекращении стачки, начав переговоры с Г. Сэмюэлем, что вызвало сильное возмущение левых лейбористов. Федерация горняков не подчинилась решению Генсовета, и шахтеры одни продолжали забастовку в течение семи месяцев, до 20 ноября 1926 года.

Стачка проходила в иных условиях, нежели рабочие выступления в начале десятилетия: не только в Англии, но и во всем мире ощущался экономический кризис, буржуазия и консервативное правительство С. Болдуина хотели выйти из него за счет рабочих. Революционный подъем в Европе уже прошел, выступления рабочих в этот период были лишь отсветами его. С точки зрения долговременной стратегии это ставило бастующих шахтеров в неблагоприятные условия в борьбе с государством. Успех мог быть обеспечен только едиными силами рабочих при руководстве Генсоветом и агитации Лейбористской партии.
Между тем соглашательство и бездействие Генсовета, проявившиеся сразу после начала всеобщей стачки, продолжались и далее. Несмотря на героическую борьбу горняков, на сочувствие им многих местных тред-юнионов, левых лейбористов, рабочих за рубежом, они одни не могли рассчитывать на победу. Вначале казалось, что они могут победить: страна начала испытывать топливный голод. Но руководство союза железнодорожников и союза транспортных рабочих пошли на соглашение с правительством, и завоз угля из-за границы, вопреки требованиям и просьбам шахтеров, увеличивался. В прессе началась травля руководства горняков, в частности, секретаря Федерации горняков А. Кука.

Только коммунисты и левые лейбористы развернули агитацию за организацию помощи горнякам.

Левые, группирующиеся вокруг газеты «Lansbury's Labour Weekly», поддержали возникшие в ряде мест советы действия, выступив за их создание повсеместно для организации помощи рабочим и их семьям, для мобилизации общественного мнения в поддержку горняков.

Выступив одним из организаторов фонда помощи горнякам и их семьям, газета вместе с коммунистами потребовала установить дополнительный профвзнос в 1 шиллинг для этого фонда.

Левые лейбористы подвергли резкой критике лидеров союза железнодорожников Д. Томаса и отчасти С. Крэмпа за отказ поддержать шахтеров.

Они вели жесткую полемику с лейбористским руководством и правым руководством тред-юнионов по поводу их позиции, выраженной Д.Р. Макдональдом, Дж. Клайнсом, Д. Томасом и другими в лозунге «Никогда снова», который означал выступление против всеобщей стачки как оружия, которое дорого обходится самим забастовщикам. Левые лейбористы выражали несогласие с их определением использования всеобщей стачки в политических целях как «лунатизма». Генсовет подвергся критике за срыв стачки и за отсутствие с его стороны всякого руководства в момент ее подготовки. В то же время газета «Lansbury's Labour Weekly» обращалась к официальному 
руководству с призывом возглавить дальнейшую борьбу [9, June 12, p. 8-9].

Но правительство, увидев брешь в самом рабочем движении, в позиции руководства, твердо решило заставить горняков принять свои условия. Была развязана кампания против сбора средств, в частности передачи горнякам помощи от рабочих Советского Союза. Генсовет тоже включился в эту кампанию, объявив, будто передача средств горнякам является вмешательством иностранного государства во внутренние дела Великобритании, что денежные средства в СССР собираются не профсоюзами и не добровольно, а в принудительном порядке, что деньги присваиваются А. Куком, хотя руководство горняков постоянно отчитывалось в их распределении. Денежные средства поступали и из Британии и других стран, хотя львиная их доля (почти 1 млн ф.ст.) была собрана советскими рабочими [1, с. 17].

В период стачки левые лейбористы выступали в печати с критикой Генсовета, исполкома Лейбористской партии, правых лидеров тред-юнионов, виновных в срыве всеобщей забастовки и в отказе от эмбарго на ввоз угля. Левые лейбористы агитировали за помощь шахтерам, собирали средства для их семей. Они резко критиковали БКТ за отклонение от кампании помощи шахтерам и создания специального фонда помощи горнякам и членам их семей. Эта критика и агитация находили поддержку во многих местных лейбористских организациях. Сбор денежных средств был организован и НРП, Ф. Брокуэй (НРП) совместно с Федерацией горняков во время всеобщей стачки выпускал газету-бюллетень стачки «Британский рабочий». Он вспоминал: «...первый раз британская газета делалась под контролем рабочих. Я никогда, работая, не испытывал такого счастья» [6, p. 190]. Д. Стрэчи и Г. Брэйлсфорд (НРП) на общественных началах редактировали газету «Горняк», а руководимая Ф. Хоррэбином Лига плебса посвятила всеобщей стачке специальный номер своего журнала «Плебс». Подробно освещалась забастовка на страницах «Lansbury's Labour Weekly».

БКТ опасался, что стачка станет политической, и Федерация горняков учла это, не выставив требования национализации, хотя лозунг национализации шахт был очень популярен в Федерации, и даже Г. Сэмюэль являлся сторонником этой меры. Тем не менее стачка все равно приобрела политический характер, поскольку в нее вмешалось государство, предъявив шахтерам свои условия.

Когда участились случаи выхода горняков на работу, колебание проявили и сами руководители горняков Г. Смит и А. Кук. Надеясь на помощь Генсовета, они сняли с повестки дня очередного съезда БКТ в Борнемуте обсуждение вопроса о всеобщей стачке и ее последствиях, по существу отказавшись от выполнения принятой значительным большинством голосов резолюции конференции горняков Южного Уэльса об укреплении дисциплины внутри союзов и о продолжении стачки. В репортаже Э. Уилкинсон с Борнемутского съезда тред-юнионов критике подвергся не только Генсовет, но и левые члены, которые на съезде молчали [9, June 19, p. 9; Aug. 28, p. 8-9; Sept. 11, p. 8-9]. Газета писала, что поражение было предопределено, так как Генсовет с самого начала не был готов к такой стачке и не верил в победу [9, Мау 22, р. 16]. «Мы увидели наших братьев разбитыми изза слабости наших лидеров», - писала газета [9, Nov. 20, p. 9]. Эти колебания имели губительные последствия. После прекращения стачки рабочие возвратились на работу на более жестких условиях, чем предлагалось вначале. Это разрушало горнодобывающую промышленность и привело к параличу массового рабочего движения на много лет. Стачка горняков и предшествующая ей всеобщая стачка показали недооценку левыми лейбористами государства как классового органа, что было в какой-то степени учтено леволейбористским движением в последующие годы.

В обстановке усиливающегося давления на горняков сверху, кампании, развязанной против них в печати, колебаний, проявленных самим руководством Федерации, левые лейбористы порой также присоединялись к этим нападкам, что было во многом результатом разногласий в их среде и их представлений о путях к социализму. «Lansbury's Labour Weekly» в редакционной статье по поводу съезда БКТ и уроков стачки, защищая личную честность А. Кука, по сути обвиняла горняков в неподчинении решению Генсовета 
прекратить забастовку. В статье говорилось, что в результате этого горняки остались без руководства, Генсовет же не мог руководить ей, не получив полномочий от горняков, хотя тут же признавалось, что Генсовет и не помышлял руководить стачкой и не верил в нее с самого начала [10, June 22, p. 9].

Д. Коул в этом же номере писал, что критика делу не поможет и нечего обвинять руководство. «Люди часто терпят поражение при выполнении большой работы не потому, что они вероломны, а потому, что поставленная задача слишком велика для их способностей» [10, June 22, p. 9]. Отмечая, что Генсовет не верил в успех забастовки с самого начала, Д. Коул не ставил вопрос о негодности и смене руководства рабочего движения, об ответственности исполкома Лейбористской партии и фактически присоединялся к критикам горняков.

Сам Д. Лэнсбери в связи с поражением стачки писал, что «дело не в лидерах, а в принципах, поэтому не надо обвинять лидеров. Ведь если лидеры умрут, движение не остановится» [10, Jan 22, p. 9]. Д. Лэнсбери фактически ставил на одну доску А. Кука и Д. Томаса, и лидеров, и массы, которые за ними следовали. Фактически он как бы оправдывал руководство, аргументируя это формулой, что рядовая масса позволяет говорить и действовать другим вместо себя [10, Jan 22, p. 9], и пока так будет, руководство не будет чувствовать ответственности перед ней.

Призывая к конструктивной критике, левые лейбористы сами не выдвигали конструктивных предложений относительно движения в целом, за исключением плана реорганизации БКТ. Близкий по воззрениям к Д. Лэнсбери А.Д. Скурр без обиняков призывал к единству движения, отказавшись от взаимных обвинений в некомпетентности и предательстве $[10, \operatorname{Jan} 8$, p. 6]. Таков был основной тон газеты после стачки.

Призывая отказаться от взаимных обвинений, левые лейбористы не выдвигали предложений по улучшению организации самого рабочего движения, кроме планов реорганизации БКТ. Они связывали с всеобщей стачкой надежды добиться национализации и контроля рабочих над производством, некоторые считали возможным таким путем прийти к социализму. Но при анализе причин поражения стачки в ответ на попытки объявить и всеобщую, и последующую стачку горняков неконституционными справедливо отмечали, что политической стачку сделало вмешательство правительства. При этом они обвинили горняков в недисциплинированности, рассматривая стачку как нормальный конституционный конфликт с обязательным подчинением высшему руководству. Вопрос об ответственности Генсовета и исполкома Лейбористской партии практически не ставился.

Иной была позиция Г.Н. Брэйлсфорда, редактора газеты НРП «Labour Leader», который с самого начала считал, что стачка горняков должна носить экономический характер. Но при анализе причин ее поражения он ставил вопрос о необходимости объединения действий профсоюзного и политического крыла. При этом он обвинял лидеров Лейбористской партии в пособничестве буржуазии, когда они включились в общий обвинительный хор и заявляли, будто стачка была инспирирована коммунистами [16, June 25 , p. 9; July 9, p. 8-9].

Однако та же группа «Lansbury's Labour Weekly» была права, когда выступала против новой забастовки, направленной против принятого после поражения горняков антипрофсоюзного закона, запретившего создание забастовочных фондов и пикетирование, разрешавшего использовать военную силу против забастовщиков. Выступая против закона, эта группа отмечала, что в обстановке кризиса и жестокого наступления реакции, обескровленности и разочарования рабочих забастовка ничего дать не могла, кроме вреда для рабочего движения. Призывать к всеобщей стачке в этих условиях, говорили они, - «опасный романтизм» $[10$, May 14 , p. $8-9$; May 26, p. $8-$ 9; July 2, p. 8-9; July 6, p. 13].

В то же время являются несостоятельными обвинения всей НРП и левых лейбористов в предательстве, высказанные некоторыми членами компартии [7, p. 115, 226, 234].

С другой стороны, стачка показала очевидную необходимость объединения левых сил в профсоюзах, партии, стране, в какой-то степени стачка поколебала представления о надклассовом государстве. И значительная часть левых сделала выводы в этом духе. 
Левые активисты профсоюзов настаивали, чтобы контроль за производственными конфликтами принадлежал не Генсовету, а самим профсоюзам. В отличие от руководства Лейбористской партии, заявлявшего, что всеобщая стачка ничего, кроме вреда, принести не могла, что никогда в будущем не следует допускать всеобщей стачки, левые лейбористы настаивали на объединении на платформе производственных профсоюзов, классовой борьбы за социалистическое будущее.

Автор статьи в «Lansbury's Labour Weekly» писал, что многие лидеры тред-юнионов «не верят в социализм, и не входят в Лейбористскую партию, многие хорошие тред-юнионисты не социалисты» [10, Febr. 19, p. 13], и поэтому руководящая роль в промышленных конфликтах должна быть не за тред-юнионами и Генсоветом, а за Лейбористской партией. Аргументом в пользу такого решения они считали бездействие Генсовета во время всеобщей стачки 1926 года.

Поражение всеобщей стачки, вызвав определенные колебания в рядах левого крыла и выявив определенную непоследовательность левых лейбористов, в условиях наступившей реакции и спада рабочего движения способствовало отходу ряда их лидеров с левых позиций, ослаблению позиций левых в профсоюзах.

Всеобщая стачка 1926 г. в Англии была последней вспышкой массового рабочего движения, отсвета того подъема, который был вызван Октябрьской революцией в России.

Но в условиях пробуждения рабочего движения в современной России ее уроки являются актуальными. Сегодня опять на повестке дня встали вопросы национализации ключевых отраслей экономики и народного контроля. Отсутствие единства, решительного руководства со стороны профсоюзов и левых политических сил, чего не хватало английским рабочим в 1926 г., характерно для этих выступлений трудящихся.

В условиях оживления идеи социализма во всем мире сегодня многие из уроков всеобщей стачки 1926 г. и обращение к теории и практике левого лейборизма, с его ошибками и недостатками, могут быть интересны и небесполезны, в частности, в Великобритании.

\section{СПИСОК ЛИТЕРАТУРЫ}

1. Арнот, Р. П. Английские горняки в годы кризиса и войны / Р. П. Арнот. - М. : Прогресс, 1964. $-463,[1] \mathrm{c}$.

2. Блосфельд, Е. Г. Английский левый лейборизм, 1918-1945 / Е. Г. Блосфельд. - Саратов : Изд-во Сарат. ун-та, 1991. - 173, [1] с.

3. Гурович, П. В. Стачка горняков 1926 года / П. В. Гурович, А. Г. Судейкин // Проблемы британской истории : сб. науч. ст. / под ред. М. Г. Жигалова. - М. : Наука, 1987. - С. 62-81.

4. Мочалов, Л. В. Марксистско-ленинская оценка фабианского социализма / Л. В. Мочалов. М. : Изд-во МГУ, 1976. - 88 с.

5. Barron, H. The 1926 Miners' Lockout: Meanings of Community in the Durham Coalfield / H. Barron. Oxford: Oxford University Press, 2010. - 320 p.

6. Brockway, F. Inside the Left / F. Brockway. L. : G. Allen \& Unwin, 1947. - 352 p.

7. Dutt, R.P. Socialism and the Living Wage / R. P. Dutt. - L. : Communist Party of Great Britain, 1927.$238 \mathrm{p}$.

8. Lansbury's Labour Weekly. - 1925.

9. Lansbury's Labour Weekly. - 1926.

10. Lansbury's Labour Weekly. - 1927.

11. Laybourn, K. The General Strike of 1926 / K. Laybourn. - Manchester : Manchester University Press, 1993. - $161 \mathrm{p}$.

12. Middlemas, R. K. Clydesiders: A Left-Wing Struggle for Parliamentary Power / R. K. Middlemas. L. : Hutchinson, 1965. $-307 \mathrm{p}$.

13. Moore, R. Emergency of the Labour Party. 1880-1924 / R. Moore. - L. : Hodder and Stoughton, 1978. - VIII, 216p.

14. Perkins, A. A Very British Strike: 3-12 May 1926 / A. Perkins. - L. : Macmillan, 2006. -356 p.

15. The New Leader. -1924.

16. The New Leader. -1926.

17. Report of the 27th Annual Conference of the Labour Party. - L. : Labour Party, 1927.

18. Sunday Worker. -1925 .

\section{REFERENCES}

1. Arnot R.P. Angliyskie gornyaki v gody krizisa $i$ voyny [English Miners in the Years of Crisis and War]. Moscow, Progress Publ., 1964. 463, [1] p.

2. Blosfeld E.G. Angliyskiy levyy leyborizm, 1918-1945 [English Left Labour, 1918-1945]. Saratov, Izd-vo Sarat. un-ta, 1991. 173, [1] p.

3. Gurovich P.V. Sudeykin A.G. Stachka gornyakov 1926 goda [The Strike of Miners in 1926]. Zhigalov M.G., ed. Problemy britanskoy istorii: sb. nauch. st. [The Problems of British History: Collection 
of Research Articles]. Moscow, Nauka Publ., 1987, pp. 62-81.

4. Mochalov L.V. Marksistcko-leninskaya otsenka fabianskogo sotsializma [Marxist-Leninist Evaluation of Fabian Socialism]. Moscow, Izd-vo MGU, 1976. 88 p.

5. Barron H. The 1926 Miners' Lockout: Meanings of Community in the Durham Coalfield. Oxford, Oxford University Press, 2010.320 p.

6. Brockway F. Inside the Left. L., G. Allen \& Unwin, 1947. $352 \mathrm{p}$.

7. Dutt R.P. Socialism and the Living Wage. L., Communist Party of Great Britain, 1927. 238 p.

8. Lansbury's Labour Weekly, 1925.

9. Lansbury's Labour Weekly, 1926.

10. Lansbury's Labour Weekly, 1927.
11. Laybourn K. The General Strike of 1926. Manchester, Manchester University Press, 1993. 161 p.

12. Middlemas R. K. Clydesiders: A Left-Wing Struggle for Parliamentary Power. L., Hutchinson, $1965.307 \mathrm{p}$.

13. Moore R. Emergency of the Labour Party. 1880-1924. L., Hodder and Stoughton, 1978. viii, $216 \mathrm{p}$.

14. Perkins A. A Very British Strike: 3-12 May 1926. L., Macmillan, 2006. 356 p.

15. The New Leader, 1924.

16. The New Leader, 1926.

17. Report of the $27^{\text {th }}$ Annual Conference of the Labour Party. L., Labour Party, 1927.

18. Sunday Worker, 1925.

\section{Information about the Author}

Evgeniya G. Blosfeld, Doctor of Sciences (History), Professor, Department of World History and Methods of Teaching History and Social Sciences, Volgograd State Social-Pedagogical University, Prosp. Lenina, 27, 400013 Volgograd, Russian Federation, genhist@vspu.ru, https://orcid.org/0000-00021790-276X

\section{Информация об авторе}

Евгения Григорьевна Блосфельд, доктор исторических наук, профессор кафедры всеобщей истории и методики преподавания истории и обществоведения, Волгоградский государственный социально-педагогический университет, просп. Ленина, 27, 400013 г. Волгоград, Российская Федерация, genhist@vspu.ru, https://orcid.org/0000-0002-1790-276X 